\title{
Prevalence of Comorbidities and its Impacts in Hospitalized Patients with COVID-19
}

\author{
Mohammad Ali Khaksar ${ }^{*}$, Elham Zanganeh Yousefabadi², Reza Taleb Zadeh'1, Homeira Rashidi', \\ Mahmood Maniati ${ }^{4}$ Nima Bakhtiari ${ }^{5}$
}

\author{
'Student Research Committee, Ahvaz Joundishapour University of Medical Sciences, Ahvaz, Iran. \\ 2Department of Internal Medicine, Jundishapour University of Medical Sciences, Ahvaz, Iran. \\ 3Diabetes Research Center, Jundishapour University of Medical Sciences, Ahvaz, Iran. \\ ${ }^{4}$ Department of General Courses, School of Medicine, Ahvaz Jundishapur University of Medical Sciences, Ahvaz, Iran. \\ 5Pain Research Center, Jundishapur University of Medical Sciences, Ahvaz, Iran. \\ ${ }^{*}$ Correspondence to: Mohammad Ali Khaksar (E-mail: khaksar.ma@ajums.ac.ir) \\ (Submitted: 10 July 2021 - Revised version received:02 August 2021 - Accepted: 25 August 2021 - Published online: 26 October 2021)
}

\begin{abstract}
Objectives: The purpose of this study is to evaluate the prevalence of comorbidities in hospitalized COVID-19 patients and its effects on the severity of the disease. The coronavirus pandemic has been a challenging problem for health care systems since December 2019.

Methods: This was a retrospective, cross-sectional study analyzing data related to the epidemiological characteristics of COVID-19 patients admitted to Razi Hospital in Ahvaz, Iran from November 2020 to February 2021. The data on patient demographic characteristics including age, gender, and underlying diseases were collected from patient records. Patients whose data were unavailable or incomplete were excluded from the study.

Results: The mean age of all of the 730 patients studied was $56.30 \pm 16.36$ years, and $53.7 \%$ of them were men. Nearly $40 \%$ of the patients reported more than one comorbidity, with diabetes mellitus being the most frequent one (37.5\%) followed by hypertension (35.3\%) and ischemic heart disease (24.9). In addition, 21.5\% of the patients required intensive care unit admission. Finally, 11.9\% of the patients had respiratory distress and became intubated, and approximately $13.6 \%$ of the patients died. Hyperlipidemia, liver failure, tuberculosis, and elevated inflammatory biomarkers are risk factors for ICU admission and death.

Conclusion: We found that male gender, older age, hyperlipidemia, liver failure, TB, having more than one comorbidity, and elevated inflammatory biomarkers were significantly associated with the risk of severe COVID-19 disease.

Keywords: Comorbidities, COVID-19, hospitalized patients
\end{abstract}

\section{Introduction}

In December, 2019, several cases of pneumonia of unknown origin were reported in Wuhan, Hubei Province, China. The disease spread to China and other countries of the world rapidly. The cause of this viral infection was later found to be a virus from the coronavirus family which was detected by a sample of patients' throat swabs. Subsequently, it was named 2019 nCOV by WHO. As the infection swept alarmingly across the globe, WHO announced it as an epidemic and it came to be known as COVID-19.

Comorbidities are one of the factors that contribute to the severity of COVID-19 disease. Throughout the world, researchers have been investigating risk factors that deteriorate the condition of COVID-19 patients. Various studies have shown that diabetes mellitus, hypertension, and cardiovascular diseases have been common comorbidities in COVID-19 patients that are associated with poor prognosis of the disease and an increased chance of hospitalization and mortality. ${ }^{2-4}$

Given the increasing prevalence of the disease, it is almost impossible to prevent its spread, and since there is no definitive treatment for this disease, it is recommended that health systems focus on preventive measures and factors contributing to the severity of the disease.

According to previous COV epidemics including SARS COV which throughout China in 2003 and MERS CVV affecting the Middle East in $2012^{6,7}$ and due to the uncertain future of the covid-19 epidemic and possible future epidemics that there is no definitive treatment during the epidemic time and also due to limited medical facilities, health care systems must notice to factors such as comorbidities that affect disease severity and its mortality.

The present study aims to evaluate the prevalence of comorbidities and their correlation with prognosis and mortality rate in COVID-19 patients in the south of Iran.

\section{Materials and Methods \\ Patients and Data Gathering}

This was a retrospective, cross-sectional study that was carried out at the Razi hospital, Ahvaz, Iran, after receiving approval from the Research Ethics Committee of Ahvaz Jundishapur University of Medical Sciences (IR.AJUMS.REC.1399.867). The present study evaluated 730 patients who had been infected with COVID-19 and hospitalized in November 2020 to February 2021. To this aim, we evaluated and extracted data from medical records of patients who were diagnosed with COVID-19 infection based on a positive RT-PCR test or typical radiological manifestations on a spiral chest CT scan.

Initially, the patients were investigated in terms of the severity of the disease (including patients with underlying diseases such as cardiovascular disease, hypertension, diabetes, underlying respiratory diseases, and BMI over 40 as well as immunocompromised patients such as those with a history of taking corticosteroids, chemotherapy, malignancies, transplantation, and HIV-positivity). The patients were divided into two groups, namely the Severe group involving patients requiring intensive care unit, and the non-severe group 
including patients who did not need intensive care unit and were admitted in the general ward.

Since no electronic medical record system was available at the time of hospitalization of the patients, patient data were recorded by physicians and nurses in patient paper medical records. Data about the underlying disease was determined according to the patients' self-declaration at the time of admission.

COVID-19 patients with unavailable or incomplete data were excluded from the study.

To collect data on the patients' underlying disease, the information about the underlying disease was first categorized (yes vs. no), and then the number of underlying diseases (single vs. multiple) was collected.

During the hospitalization period, the patients were examined on a daily basis by specialist physicians, and patient's information and vital signs were recorded manually and accurately by physicians and nurses in the patients' medical record. The recorded data included admission at the general ward, admission at the ICU, duration of admission at the ICU, need for mechanical ventilation, discharge from the hospital, duration of hospitalization, and death.

\section{Statistical Analysis}

In this study, the data were analyzed using SPSS version 24 (IBM Corp., Armonk, NY, USA). Continuous (normally distributed) variables were represented as means \pm SDs with $95 \%$ confidence intervals (CI), and percentiles, frequencies, and percentages were used for categorical variables. Non-normally distributed variables were represented as medians with $25 \%$ and $75 \%$ values. Mann-Whitney $U$ test was used for nonnormally distributed variables. The $\chi^{2}$ test, or Fisher's exact test, was used to compare categorical variables between groups, while Spearman rho test, was used to compare continuous (Non-normally) variables between groups. A $P<0.05$ was considered statistically significant.

\section{Results}

In the present study, we investigated 730 patients whose mean age was $56.30 \pm 16.36$, and $53.7 \%$ of them were male. Onethird of the patients had no comorbidity while the rest had at least one comorbidity. The most common comorbidity was diabetes mellitus (37.5\%) followed by hypertension (35.3\%), ischemic heart disease (24.9\%) and hyperlipidemia (11\%). Other clinical characteristics are presented in Table 1.

Totally, out of the 730 patients, 157 (21.5\%) were admitted to the intensive care unit (ICU), and the rest were admitted to general wards (78.5\%). According to our results, patients who had been admitted to ICU were significantly older than those admitted to general wards (mean 26/17 \pm 86/60 years vs. $89 / 15 \pm 05 / 55$ years, $P=001 / 0$ ). More males than women were admitted to ICU, but the difference was not significant (93(23.7\%) versus $64(18.9 \%) P=0.125)$. In addition, we found that ICU admission was significantly associated with hyperlipidemia $(P: 0.014)$, liver failure $(P: 0.026)$, and tuberculosis $(P<0.022)$. Patients who had more comorbidities were more likely to be admitted to ICU. Also, patients who were admitted to ICU had significantly higher inflammatory biomarkers like ESR $(P: 0.008), \mathrm{CRP}(P<0.001)$, and LDH $(P:<0.001)$. The length of stay at ICU was longer for patients who were older $(P<0.001)$ and had hyperlipidemia $(P: 0.015)$,

\begin{tabular}{|c|c|}
\hline Demographic data & $n(\%)$ \\
\hline \multicolumn{2}{|l|}{ Age (year) } \\
\hline Mean \pm SD & $56.30 \pm 16.36$ \\
\hline Min - Max & $21-104$ \\
\hline \multicolumn{2}{|l|}{ Sex } \\
\hline Male & $392(53.7)$ \\
\hline Female & $338(46.3)$ \\
\hline \multicolumn{2}{|l|}{ History of comorbidities } \\
\hline Diabetes Mellitus & $274(37.5)$ \\
\hline Hyperlipidemia & $80(11)$ \\
\hline Hypertension & $258(35.3)$ \\
\hline Ischemic heart disease & $182(24.9)$ \\
\hline Cerebrovascular accident & $27(3.7)$ \\
\hline Rheumatoid arthritis & $17(2.3)$ \\
\hline Hypothyroidism & $24(3.3)$ \\
\hline Systemic Lupus Erythematosus & $3(.4)$ \\
\hline Asthma & $45(6.2)$ \\
\hline Liver failure & $9(1.2)$ \\
\hline Kidney transplantation & $12(1.6)$ \\
\hline Chronic kidney disease & $65(8.9)$ \\
\hline Chronic obstructive pulmonary disease & $6(0.8)$ \\
\hline Tuberculosis & $6(0.8)$ \\
\hline \multicolumn{2}{|l|}{ Comorbidity } \\
\hline 0 & $244(33.4)$ \\
\hline 1 & $194(26.6)$ \\
\hline$>1$ & $292(40)$ \\
\hline \multicolumn{2}{|l|}{ Laboratory investigations } \\
\hline \multicolumn{2}{|l|}{ Erythrocyte Sedimentation Rate } \\
\hline Mean \pm SD & $51.01 \pm 31.61$ \\
\hline Min - Max & $3-348$ \\
\hline \multicolumn{2}{|l|}{ C-reactive protein } \\
\hline Mean \pm SD & $51.44 \pm 32.16$ \\
\hline Min - Max & $1-151$ \\
\hline \multicolumn{2}{|l|}{ Lactate dehydrogenase } \\
\hline Mean $\pm S D$ & $608.93 \pm 333.56$ \\
\hline Min - Max & $85-3784$ \\
\hline \multicolumn{2}{|l|}{ Complications } \\
\hline Death & 99 (13.6) \\
\hline \multicolumn{2}{|l|}{ Outcome } \\
\hline ICU & $157(21.5)$ \\
\hline Intubation & 87 (11.9) \\
\hline \multicolumn{2}{|l|}{ Duration of hospital stay (day) } \\
\hline Mean $\pm S D$ & $7.11 \pm 4.36$ \\
\hline Min - Max & $1-38$ \\
\hline \multicolumn{2}{|l|}{ Duration of ICU stay (day) } \\
\hline Mean \pm SD & $1.35 \pm 3.54$ \\
\hline Min - Max & $0-37$ \\
\hline
\end{tabular}

Values are presented as numbers and percentages (\%). 
liver failure $(P: 0.015)$, and tuberculosis $(P: 0.006)$ in their medical history as well as those having elevated inflammation biomarkers. Other clinical characteristics are presented in Tables 2, 3, 6 .

In this study, 99 patients (13.5\%) died, and a higher mortality rate was observed among the elderly, males, patients with liver failure and tuberculosis, as well as those having more comorbidities and elevated ESR, CRP, and LDH levels. Other clinical characteristics are presented in Table 4.

In our study, no association was found between the length of stay at hospital and any comorbidity. However, patients who had elevated inflammatory bio markers were hospitalized for a longer period (Table 5).

\section{Discussion}

In this retrospective descriptive-analytical study performed in the first surge of coronavirus pandemic in Khuzestan province, Iran, we examined the effect of comorbidities on the prognosis and mortality of 730 Covid-19 patients admitted to Razi Hospital of Ahvaz, Iran. According to our results, more than half of the admitted patients were male (53.7\%), and one third of the patients had no underlying disease. However, at least one underlying disease was reported for the remaining patients, with diabetes mellitus being the most common, followed by hypertension, ischemic heart disease, and hyperlipidemia, respectively. In addition, mortality rate and the rate of ICU admission in this study were $13.6 \%$ and $21.5 \%$, respectively.

The Covid-19 pandemic in Iran has become one of the major health system challenges in recent decades. Because older people are at a greater risk for complications of Covid-19 owing to the effects of aging on the immune system, in our study, as in other studies, older people were more likely to develop the severe form of the disease as attested by their greater need for ICU admission and their high mortality rate. Also, previous studies on SARS and MERS have shown that old age is associated with higher mortality rates. ${ }^{8-11}$

The results of Pijls et al. showed that the risk of developing Covid-19 disease, the severity of the disease, the need for hospitalization in the intensive care unit (ICU), and the mortality rate in men with Covid-19 are higher. ${ }^{12}$ Also, the results of another study conducted in Iran showed that men were more likely to get Covid-19 than women, while there was no significant difference in the severity of the disease between the sexes. ${ }^{11}$ In the present study, men had a higher risk of getting the disease in general and the severe form of the disease in particular, which could be due to the more pronounced presence of men in the community, taking care of economic issues, and lack of proper observance of health protocols such as wearing masks and social distancing. Also, the high level of ACE2 in men can justify this difference. ${ }^{13}$ In this study, the mortality rate was higher in men but the need for ICU hospitalization in men was not significantly different from that of women.

Guan et al. reported that $25.1 \%$ of their patients had at least one underlying disease, and the most common comorbidities were hypertension (16.9\%) and diabetes (8.2\%), respectively. ${ }^{3}$ Another study by Liu et al. showed that $19.7 \%$ of patients with Covid-19 had comorbidities, with diabetes (10.2\%) being the most common, followed by hypertension (9.5\%) and cardiovascular disease (7.3\%). ${ }^{4} \mathrm{~A}$ similar study conducted in Iran showed that the prevalence of comorbidities in patients with coronavirus was $48.8 \%$ and the prevalence of internal diseases and coronary artery disease were $29.3 \%$ and $14.6 \%$, respectively. ${ }^{11}$ In the present study, two thirds of patients reported at least one underlying disease, with the most underlying disease being diabetes mellitus (37.5\%) followed by hypertension $(35.3 \%)$, ischemic heart disease $(24.8 \%)$ and hyperlipidemia (11\%).

In the present study, $37.5 \%$ of the patients mentioned diabetes in their past medical history, which was higher than the rate reported in other studies and could be attributed to the high prevalence of diabetes in Khuzestan province, ${ }^{14}$ the high risk of COVID-19 among diabetic patients, high disease severity, and hospitalization, ${ }^{15}$ This result can also be justified by the tendency of physicians to hospitalize diabetic patients with COVID-19 who have uncontrolled blood sugar due to insulin deficiency in Iran and the strict protocols of the studied hospital in the first surge of COVID-19 regarding the hospitalization of patients with underlying disease and those with mild severity. Other possible causes are differences in thresholds for hospitalization.

Among other important comorbidities in this study, hypertension, ischemic heart disease, and hyperlipidemia are the notable, and their prevalence was high compared to similar studies., ${ }^{411}$ This can be explained by the high prevalence of obesity, hypertension and hyperlipidemia in Khuzestan province and the ignorance of the many people living there of their diseases, which constitute the main risk factors for coronary artery disease in this region. ${ }^{16,17}$ Again, this result can be attributed to the protocols of our medical center regarding hospitalization of patients.

Various studies have shown that diabetes, hypertension, cardiovascular disease, cerebrovascular accidents, chronic obstructive pulmonary disease, and chronic kidney disease can predispose patients to severe disease and various complications. ${ }^{18,19}$ Two studies in China found that hypertension, cardiovascular disease, and cerebrovascular events were significantly associated with disease severity, while diabetes was not associated with disease severity. ${ }^{20,21}$ In the present study, cerebrovascular accidents and chronic kidney disease were correlated with the rate of intubation, which could be due to the high risk of respiratory failure in the underlying disease. In another study conducted in Iran, patients with chronic kidney disease were reported to have a higher chance of developing a severe form of the disease compared with the general population, ${ }^{22}$ We also found no association between other underlying diseases and the severity of the disease, which could be due to our center's protocols regarding the hospitalization of patients with mild underlying disease. Many patients also use RAAS inhibitors, which can improve patients outcomes. ${ }^{23}$ Another cause of this can be the immediate control of underlying diseases by doctors and medical staff in our center. However, in this study, the more the underlying disease of the patients, the higher the mortality rate.

In the present study, hyperlipidemia, liver failure and tuberculosis had a significant relationship with high mortality and hospitalization in ICU. However, in a systematic review and meta-analysis study by Fang et al., no association disease was found between the mentioned factors and disease severity, ${ }^{19}$ In another study by Chen et al. tuberculosis and chronic liver disease had no association with disease severity. ${ }^{24}$ One more study in China found that hyperlipidemia was not associated with disease severity and mortality. ${ }^{25}$ The relationship between liver disease and disease severity can be due to 


\begin{tabular}{|c|c|c|c|}
\hline Demographic data & $\begin{array}{l}\text { Non-ICU } \\
n=416\end{array}$ & $\begin{array}{c}\text { ICU } \\
n=352\end{array}$ & $P$-value \\
\hline Age (year) (Mean \pm SD) & $55.05 \pm 15.89$ & $60.86 \pm 17.26$ & $<0.001^{*}$ \\
\hline \multicolumn{4}{|l|}{ Sex } \\
\hline Male & $299(52.2)$ & $93(59.2)$ & 0.125 \\
\hline Female & $274(47.8)$ & $64(40.8)$ & \\
\hline \multicolumn{4}{|l|}{ History of comorbidities } \\
\hline Diabetes Mellitus: Yes & $209(76.3)$ & $65(23.7)$ & 0.265 \\
\hline No & $364(79.8)$ & $92(20.2)$ & \\
\hline Hyperlipidemia: Yes & $54(67.5)$ & $26(32.5)$ & $0.014^{*}$ \\
\hline No & $519(79.8)$ & $131(20.2)$ & \\
\hline Hypertension: Yes & $194(75.2)$ & $64(24.8)$ & 0.11 \\
\hline No & $379(80.3)$ & 93 (19.7) & \\
\hline Ischemic heart disease: Yes & $134(73.6)$ & $48(26.4)$ & 0.076 \\
\hline No & $439(80.1)$ & $109(19.9)$ & \\
\hline Cerebrovascular accident: Yes & $17(63)$ & $10(37)$ & 0.056 \\
\hline No & $556(79.1)$ & $147(20.9)$ & \\
\hline Rheumatoid arthritis: Yes & $14(82.4)$ & $3(17.6)$ & $>0.99$ \\
\hline No & $559(78.4)$ & $154(21.6)$ & \\
\hline Hypothyroidism:Yes & $22(91.7)$ & $2(8.3)$ & 0.133 \\
\hline No & $551(78)$ & $155(22)$ & \\
\hline Systemic Lupus Erythematosus: Yes & $3(100)$ & $0(0)$ & $>0.99$ \\
\hline No & $570(78.4)$ & $157(21.6)$ & \\
\hline Asthma: Yes & $38(84.4)$ & $7(15.6)$ & 0.453 \\
\hline No & $535(78.1)$ & $150(21.9)$ & \\
\hline Liver failure: Yes & $4(44.4)$ & $5(55.6)$ & $0.026^{*}$ \\
\hline No & $569(78.9)$ & $152(21.1)$ & \\
\hline Kidney transplantation: Yes & $11(91.7)$ & $1(8.3)$ & 0.478 \\
\hline No & $562(78.3)$ & $156(2.7)$ & \\
\hline Chronic kidney disease: Yes & $48(73.8)$ & $17(26.2)$ & 0.344 \\
\hline No & $525(78.9)$ & $140(21.1)$ & \\
\hline Chronic obstructive pulmonary disease: Yes & $4(66.7)$ & $2(33.3)$ & 0.614 \\
\hline No & $569(78.6)$ & $155(21.4)$ & \\
\hline Tuberculosis: Yes & $2(33.3)$ & $4(66.7)$ & $0.022^{*}$ \\
\hline No & $571(78.9)$ & $153(21.1)$ & \\
\hline \multicolumn{4}{|l|}{ Comorbidity } \\
\hline 0 & $201(35.1)$ & $43(27.4)$ & \\
\hline 1 & $154(26.9)$ & $40(25.5)$ & 0.091 \\
\hline$>1$ & $218(38)$ & $74(47.1)$ & \\
\hline \multicolumn{4}{|l|}{ Laboratory investigations } \\
\hline Erythrocyte Sedimentation Rate (Mean \pm SD) & $49.37 \pm 31.02$ & $57 \pm 33.09$ & $0.008^{*}$ \\
\hline C-reactive protein (Mean \pm SD) & $47.83 \pm 31.10$ & $64.59 \pm 32.65$ & $<0.001^{*}$ \\
\hline Lactate dehydrogenase (Mean \pm SD) & $553.8 \pm 259.4$ & $809.7 \pm 470.4$ & $<0.001^{*}$ \\
\hline
\end{tabular}

Values are presented as numbers and percentages (\%). ${ }^{*} P$-value $<0.05$ is significant. 


\begin{tabular}{|c|c|c|c|}
\hline Demographic data & $\begin{array}{c}\text { non-intubation } \\
n=416\end{array}$ & $\begin{array}{c}\text { intubation } \\
n=352\end{array}$ & $P$-value \\
\hline Age (year) $($ Mean \pm SD) & $55.21 \pm 16.05$ & $64.38 \pm 16.45$ & $<0.001^{*}$ \\
\hline \multicolumn{4}{|l|}{ Sex } \\
\hline Male & $336(52.3)$ & $56(64.4)$ & $0.039^{*}$ \\
\hline Female & $307(47.7)$ & $31(35.6)$ & \\
\hline \multicolumn{4}{|l|}{ History of comorbidities } \\
\hline Diabetes Mellitus: Yes & $236(86.1)$ & $38(13.9)$ & 0.238 \\
\hline No & 407 (89.3) & $49(10.7)$ & \\
\hline Hyperlipidemia:Yes & $67(83.8)$ & $13(16.3)$ & 0.203 \\
\hline No & $576(88.6)$ & $74(11.4)$ & \\
\hline Hypertension: Yes & $220(85.3)$ & $38(14.7)$ & 0.094 \\
\hline No & $423(89.6)$ & $49(10.4)$ & \\
\hline Ischemic heart disease: Yes & $154(84.6)$ & $28(15.4)$ & 0.065 \\
\hline No & $489(89.2)$ & $59(10.8)$ & \\
\hline Cerebrovascular accident: Yes & $20(74.1)$ & $7(25.9)$ & $0.032^{*}$ \\
\hline No & $623(88.6)$ & $80(1.4)$ & \\
\hline Rheumatoid arthritis: Yes & $15(88.2)$ & $2(11.8)$ & $>0.99$ \\
\hline No & $628(88.1)$ & 85 (11.9) & \\
\hline Hypothyroidism:Yes & $23(95.8)$ & $1(4.2)$ & 0.34 \\
\hline No & $620(87.8)$ & $86(12.2)$ & \\
\hline Systemic Lupus Erythematosus: Yes & $3(100)$ & $0(0)$ & $>0.99$ \\
\hline No & $640(88)$ & $87(12)$ & \\
\hline Asthma: Yes & $42(93.3)$ & $3(6.7)$ & 0.346 \\
\hline No & $601(87.7)$ & $84(12.3)$ & \\
\hline Liver failure: Yes & $6(66.7)$ & $3(33.3)$ & 0.081 \\
\hline No & $637(88.3)$ & $84(11.7)$ & \\
\hline Kidney transplantation: Yes & $12(100)$ & $0(0)$ & 0.378 \\
\hline No & $631(87.9)$ & $87(12.1)$ & \\
\hline Chronic kidney disease: Yes & $52(80)$ & $13(20)$ & $0.044^{*}$ \\
\hline No & $591(88.9)$ & $74(11.1)$ & \\
\hline Chronic obstructive pulmonary disease: Yes & $5(83.3)$ & $1(16.7)$ & 0.534 \\
\hline No & $638(88.1)$ & $86(1.9)$ & \\
\hline Tuberculosis: Yes & $2(33.3)$ & $4(66.4)$ & $0.002^{*}$ \\
\hline No & $641(88.5)$ & $83(11.5)$ & \\
\hline \multicolumn{4}{|l|}{ Comorbidity } \\
\hline 0 & $221(34.4)$ & $23(26.4)$ & 0.060 \\
\hline 1 & $175(27.2)$ & $19(21.8)$ & \\
\hline$>1$ & $247(38.4)$ & $45(51.7)$ & \\
\hline \multicolumn{4}{|l|}{ Laboratory investigations } \\
\hline Erythrocyte Sedimentation Rate (Mean \pm SD) & $49.60 \pm 40$ & $61.41 \pm 34.21$ & $0.001^{*}$ \\
\hline C-reactive protein (Mean \pm SD) & $49.01 \pm 31.53$ & $69.41 \pm 31.24$ & $<0.001^{*}$ \\
\hline Lactate dehydrogenase (Mean \pm SD) & $567.2 \pm 262.8$ & $920.9 \pm 565.4$ & $<0.001^{*}$ \\
\hline
\end{tabular}

Values are presented as numbers and percentages (\%). ${ }^{*}$-value $<0.05$ is significant. 


\begin{tabular}{|c|c|c|c|}
\hline Demographic data & $\begin{array}{l}\text { Live } \\
n=631\end{array}$ & $\begin{array}{l}\text { Death } \\
n=99\end{array}$ & $P$-value \\
\hline Age (year)(Mean \pm SD) & $54.87 \pm 16.04$ & $65.45 \pm 15.43$ & $<0.001^{*}$ \\
\hline \multicolumn{4}{|l|}{ Sex } \\
\hline Male & $328(52)$ & $64(64.6)$ & $0.023^{*}$ \\
\hline Female & $303(48)$ & $35(35.4)$ & \\
\hline \multicolumn{4}{|l|}{ History of comorbidities } \\
\hline Diabetes Mellitus: Yes & $232(31.8)$ & $42(15.3)$ & 0.315 \\
\hline No & $399(87.5)$ & $57(12.5)$ & \\
\hline Hyperlipidemia:Yes & $65(81.3)$ & $15(18.8)$ & 0.165 \\
\hline No & $566(87.1)$ & $84(12.9)$ & \\
\hline Hypertension:Yes & $214(82.9)$ & $44(17.1)$ & 0.054 \\
\hline No & $417(88.3)$ & $55(11.7)$ & \\
\hline Ischemic heart disease: Yes & $150(82.4)$ & $32(17.6)$ & 0.080 \\
\hline No & $481(87.8)$ & $67(12.2)$ & \\
\hline Cerebrovascular accident: Yes & $21(77.8)$ & $6(22.2)$ & 0.244 \\
\hline No & $610(86.8)$ & $93(13.2)$ & \\
\hline Rheumatoid arthritis: Yes & $15(88.2)$ & $2(11.8)$ & $<0.99$ \\
\hline No & $616(86.4)$ & 97 (13.6) & \\
\hline Hypothyroidism: Yes & $21(87.5)$ & $3(12.5)$ & $<0.99$ \\
\hline No & $610(86.4)$ & $96(13.6)$ & \\
\hline Systemic Lupus Erythematosus: Yes & $3(100)$ & $0(0)$ & $<.099$ \\
\hline No & $628(86.4)$ & 99 (13.6) & \\
\hline Asthma: Yes & $41(91.1)$ & $4(8.9)$ & 0.499 \\
\hline No & $590(86.1)$ & $95(13.9)$ & \\
\hline Liver failure: Yes & $4(44.4)$ & $5(55.6)$ & $0.003^{*}$ \\
\hline No & $627(87)$ & $94(13)$ & \\
\hline Kidney transplantation: Yes & $12(100)$ & $0(0)$ & 0.386 \\
\hline No & $619(86.2)$ & $99(13.8)$ & \\
\hline Chronic kidney disease: Yes & $52(80)$ & $13(20)$ & 0.127 \\
\hline No & $579(87.1)$ & $86(12.9)$ & \\
\hline Chronic obstructive pulmonary disease: Yes & $5(83.3)$ & $1(16.7)$ & 0.584 \\
\hline No & $626(86.5)$ & $98(13.5)$ & \\
\hline Tuberculosis:Yes & $2(33.3)$ & $4(0.5)$ & $0.004^{*}$ \\
\hline No & $629(86.9)$ & $95(13.1)$ & \\
\hline \multicolumn{4}{|l|}{ Comorbidity } \\
\hline 0 & $220(34.9)$ & $24(24.2)$ & $0.048^{*}$ \\
\hline 1 & $169(26.8)$ & $25(25.3)$ & \\
\hline$>1$ & $242(38.4)$ & $50(50.5)$ & \\
\hline \multicolumn{4}{|l|}{ Laboratory investigations } \\
\hline Erythrocyte Sedimentation Rate (Mean \pm SD) & $49.93 \pm 31.25$ & $57.89 \pm 33.14$ & $0.015^{*}$ \\
\hline C-reactive protein (Mean \pm SD) & $48.64 \pm 31.43$ & $69.29 \pm 31.21$ & $<0.001^{*}$ \\
\hline Lactate dehydrogenase (Mean \pm SD) & $559.3 \pm 245.8$ & $928.7 \pm 568.7$ & $<0.001^{*}$ \\
\hline
\end{tabular}

Values are presented as numbers and percentages (\%). ${ }^{*}$-value $<0.05$ is significant. 


\begin{tabular}{|c|c|c|c|c|c|}
\hline \multicolumn{3}{|c|}{$\begin{array}{l}\text { Table 5. Association between demographics and clinical } \\
\text { characteristics and duration of hospital stay (day) }\end{array}$} & \multicolumn{3}{|c|}{$\begin{array}{l}\text { Table 6. Association between demographics and clinical } \\
\text { characteristics and duration of ICU stay (day) }\end{array}$} \\
\hline \multirow[t]{2}{*}{ Demographic data } & \multirow{2}{*}{$\begin{array}{c}\text { Duration of } \\
\text { hospital stay (day) } \\
\text { (Mean } \pm \text { SD) }\end{array}$} & \multirow[t]{2}{*}{$P$-value } & Demographic data & $\begin{array}{l}\text { Duration of ICU stay } \\
\text { (day) }(\text { Mean } \pm \text { SD) }\end{array}$ & $P$-value \\
\hline & & & Age (year) (Spearman's rho) & 0.147 & $<0.001^{*}$ \\
\hline Age (year) (Spearman's rho) & 0.056 & 0.130 & Sex & & \\
\hline Sex & & & Male & $1.45 \pm 3.70$ & 0.148 \\
\hline Male & $7.35 \pm 4.60$ & 0.196 & Female & $1.24 \pm 3.35$ & \\
\hline Female & $6.83 \pm 4.05$ & & History of comorbidities & & \\
\hline History of comorbidities & & & Diabetes Mellitus & & \\
\hline Diabetes Mellitus & & & No & $1.37 \pm 3.73$ & 0.345 \\
\hline No & $7.09 \pm 4.42$ & 0.848 & Yes & $1.33 \pm 3.21$ & \\
\hline Yes & $7.15 \pm 4.27$ & & Hyperlipidemia & & \\
\hline Hyperlipidemia & & & No & $1.28 \pm 3.50$ & 0.015 \\
\hline No & $7.05 \pm 4.38$ & 0.109 & Yes & $1.91 \pm 3.88$ & \\
\hline Yes & $7.60 \pm 4.17$ & & Hypertension & & \\
\hline Hypertension & & & No & $1.28 \pm 3.63$ & 0.119 \\
\hline No & $7.07 \pm 4.44$ & 0.532 & Yes & $1.48 \pm 3.39$ & \\
\hline Yes & $7.19 \pm 4.21$ & & Ischemic heart disease & & \\
\hline Ischemic heart disease & & & No & $1.34 \pm 3.65$ & 0.117 \\
\hline No & $7.09 \pm 4.27$ & 0.693 & Yes & $1.38 \pm 3.21$ & \\
\hline Yes & $7.18 \pm 4.63$ & & Cerebrovascular accident & & \\
\hline Cerebrovascular accident & & & No & $1.34 \pm 3.56$ & 0.073 \\
\hline No & $7.11 \pm 4.35$ & 0.994 & Yes & $1.70 \pm 3.01$ & \\
\hline Yes & $7.22 \pm 4.58$ & & Rheumatoid arthritis & & \\
\hline Rheumatoid arthritis & & & No & $1.37 \pm 3.57$ & 0.659 \\
\hline No & $7.12 \pm 4.38$ & 0.779 & Yes & $0.82 \pm 2.10$ & \\
\hline Yes & $6.53 \pm 3.54$ & & Hypothyroidism & & \\
\hline Hypothyroidism & & & No & $1.39 \pm 3.59$ & 0.099 \\
\hline No & $7.12 \pm 4.39$ & 0.821 & Yes & $0.29 \pm 1.08$ & \\
\hline Yes & $6.67 \pm 3.47$ & & Systemic Lupus Erythematosus & & \\
\hline Systemic Lupus Erythematosus & & & No & $1.36 \pm 3.55$ & - \\
\hline No & $7.12 \pm 4.37$ & 0.676 & Yes & 0 & \\
\hline Yes & $5.67 \pm 2.08$ & & Asthma & & \\
\hline Asthma & & & No & $1.34 \pm 3.35$ & 0.389 \\
\hline No & $7.09 \pm 4.26$ & 0.960 & Yes & $1.58 \pm 5.77$ & \\
\hline Yes & $7.33 \pm 5.71$ & & Liver failure & & \\
\hline Liver failure & & & No & $1.33 \pm 3.52$ & $0.015^{*}$ \\
\hline No & $7.11 \pm 4.35$ & 0.669 & Yes & $3.33 \pm 4.80$ & \\
\hline Yes & $7 \pm 5.31$ & & Kidney transplantation & & \\
\hline Kidney transplantation & & & No & $1.37 \pm 3.57$ & 0.240 \\
\hline No & $7.12 \pm 4.38$ & 0.841 & Yes & $0.25 \pm 0.87$ & \\
\hline Yes & $6.50 \pm 3.34$ & & Chronic kidney disease & & \\
\hline Chronic kidney disease & & & No & $1.35 \pm 3.62$ & 0.376 \\
\hline No & $7.11 \pm 4.42$ & 0.692 & Yes & $1.35 \pm 2.68$ & \\
\hline Yes & $7.08 \pm 3.73$ & & Chronic obstructive pulmonary disease & & \\
\hline Chronic obstructive pulmonary disease & & & No & $1.33 \pm 3.46$ & \\
\hline No & $7.10 \pm 4.32$ & 0.897 & Yes & $4.67 \pm 9.20$ & 0.360 \\
\hline Yes & $8.67 \pm 8.69$ & & Tuberculosis & & \\
\hline Tuberculosis & & & No & $1.33 \pm 3.52$ & $0.006^{*}$ \\
\hline No & $7.08 \pm 4.35$ & 0.063 & Yes & $4.50 \pm 5.13$ & \\
\hline Yes & $10.50 \pm 4.97$ & & Comorbidity & & \\
\hline Comorbidity & & & 0 & $1.19 \pm 3.31$ & 0.142 \\
\hline 0 & $6.88 \pm 4.31$ & 0.358 & 1 & $1.49 \pm 4.25$ & \\
\hline 1 & $7.36 \pm 4.50$ & & $>1$ & $1.39 \pm 3.20$ & \\
\hline$>1$ & $7.14 \pm 4.31$ & & Laboratory investigations & & \\
\hline Laboratory investigations & & & Erythrocyte Sedimentation Rate & 0.089 & $0.016^{*}$ \\
\hline Erythrocyte Sedimentation Rate & 0.196 & $<0.001^{*}$ & (Spearman's rho) & & \\
\hline (Spearman's rho) & & & C-reactive protein (Spearman's rho) & 0.180 & $<0.001^{*}$ \\
\hline C-reactive protein (Spearman's rho) & 0.105 & $0.004^{*}$ & Lactate dehydrogenase & 0.256 & $<0.001^{*}$ \\
\hline Lactate dehydrogenase & 0.173 & $<0.001^{*}$ & (Spearman's rho) & & \\
\hline (Spearman's rho) & & & $P$-value $<0.05$ is signifcant. & & \\
\hline
\end{tabular}

${ }^{*} P$-value $<0.05$ is significant. 
the prohibition of taking certain drugs in patients with a history of liver problems on the one hand, and the organ failure caused by Covid-19, on the other. In our study, there was a relationship between the history of tuberculosis and high severity of the disease, which could be due to old lung damage and reduced lung reserve in these patients, as well as the reactivation of TB and TB superinfection on Covid, leading the patient to respiratory failure.

Another predictor of disease severity in various studies and ours was the high level of inflammatory markers in patients' tests, which in addition to predicting the severity of the disease, can be used as a response to treatment factor. ${ }^{20,24}$

\section{Conclusion}

1. We found that male gender, older age, hyperlipidemia, liver failure, TB, having more than one comorbidity, and elevated inflammatory biomarkers were significantly associated with the risk of severe COVID-19 disease.

\section{Declaration of Patient Consent}

The authors certify that they have obtained all appropriate patient consent forms. In the form, the patients have given their consent for their images and other clinical information to be reported in the journal. The patients understand that their names and initials will not be published and due efforts will be made to conceal their identity, but anonymity cannot be guaranteed.

\section{Financial Support and Sponsorship}

This research was supported by grants (APRD-9915) from the Air pollution respiratory Disease research Center by the Vice Chancellor of Research and Development, Ahvaz Jundishapur University of Medical Sciences (Iran).

\section{Conflicts of Interest}

There are no conflicts of interest.

\section{References}

1. Organization WH. Clinical management of severe acute respiratory infection (SARI) when COVID-19 disease is suspected: interim guidance, 13 March 2020. World Health Organization; 2020

2. Qin C, Zhou L, Hu Z, Zhang S, Yang S, Tao Y, et al. Dysregulation of immune response in patients with coronavirus 2019 (COVID-19) in Wuhan, China. Clinical infectious diseases. 2020;71(15):762-8

3. Guan W-j, Liang W-h, Zhao Y, Liang H-r, Chen Z-s, Li Y-m, et al. Comorbidity and its impact on 1590 patients with COVID-19 in China: a nationwide analysis. European Respiratory Journal. 2020;55(5).

4. Liu K, Fang Y-Y, Deng Y, Liu W, Wang M-F, Ma J-P, et al. Clinical characteristics of novel coronavirus cases in tertiary hospitals in Hubei Province. Chinese medical journal. 2020

5. Wu Z, McGoogan JM. Characteristics of and important lessons from the coronavirus disease 2019 (COVID-19) outbreak in China: summary of a report of 72314 cases from the Chinese Center for Disease Control and Prevention. Jama. 2020;323(13):1239-42.

6. Zhong N, Zheng B, Li Y, Poon L, Xie Z, Chan K, et al. Epidemiology and cause of severe acute respiratory syndrome (SARS) in Guangdong, People's Republic of China, in February, 2003. The Lancet. 2003:362(9393):1353-8.

7. Assiri A, McGeer A, Perl TM, Price CS, Al Rabeeah AA, Cummings DA, et al. Hospital outbreak of Middle East respiratory syndrome coronavirus. New England Journal of Medicine. 2013;369(5):407-16.

8. Choi KW, Chau TN, Tsang O, Tso E, Chiu MC, Tong WL, et al. Outcomes and prognostic factors in 267 patients with severe acute respiratory syndrome in Hong Kong. Annals of internal medicine. 2003;139(9):715-23.

9. Hong K-H, Choi J-P, Hong S-H, Lee J, Kwon J-S, Kim S-M, et al. Predictors of mortality in Middle East respiratory syndrome (MERS). Thorax. 2018;73(3):286-9.

10. KoffWC, Williams MA. Covid-19 and immunity in aging populations-a new research agenda. New England Journal of Medicine. 2020;383(9):804-5.

11. Zaferani Arani H, Dehghan Manshadi G, Atashi HA, Rezaei Nejad A, Ghorani SM, Abolghasemi S, et al. Understanding the clinical and demographic characteristics of second coronavirus spike in 192 patients in Tehran, Iran: A retrospective study. Plos one. 2021;16(3):e0246314

12. Pijls BG, Jolani S, Atherley A, Derckx RT, Dijkstra Jl, Franssen GH, et al. Demographic risk factors for COVID-19 infection, severity, ICU admission and death: a meta-analysis of 59 studies. BMJ open. 2021;11(1):e044640.

13. Oudit GY, Pfeffer MA. Plasma angiotensin-converting enzyme 2: novel biomarker in heart failure with implications for COVID-19. European heart journal. 2020;41(19):1818-20.
14. Yazdanpanah L, Shahbazian H, Aleali AM, Jahanshahi A, Ghanbari S, Latifi S. Prevalence, awareness and risk factors of diabetes in Ahvaz (South West of Iran). Diabetes \& Metabolic Syndrome: Clinical Research \& Reviews. 2016;10(2):S114-S8

15. Singh AK, Gupta R, Ghosh A, Misra A. Diabetes in COVID-19: Prevalence, pathophysiology, prognosis and practical considerations. Diabetes \& Metabolic Syndrome: Clinical Research \& Reviews. 2020;14(4):303-10.

16. Yazdanpanah L, Shahbazian H, Shahbazian H, Latifi S-M. Prevalence, awareness and risk factors of hypertension in southwest of Iran. Journal of renal injury prevention. 2015:4(2):51.

17. Latifi SM, Moradi L, Shahbazian H, Aleali AM. A study of the prevalence of dyslipidemia among the adult population of Ahvaz, Iran. Diabetes \& Metabolic Syndrome: Clinical Research \& Reviews. 2016;10(4):190-3.

18. Zhou F, Yu T, Du R, Fan G, Liu Y, Liu Z, et al. Clinical course and risk factors for mortality of adult inpatients with COVID-19 in Wuhan, China: a retrospective cohort study. The lancet. 2020;395(10229):1054-62

19. Fang $X$, Li S, Yu H, Wang P, Zhang Y, Chen Z, et al. Epidemiological, comorbidity factors with severity and prognosis of COVID-19: a systematic review and meta-analysis. Aging (Albany NY). 2020;12(13):12493.

20. Zhang G, Hu C, Luo L, Fang F, Chen Y, Li J, et al. Clinical features and shortterm outcomes of 221 patients with COVID-19 in Wuhan, China. Journal of Clinical Virology. 2020;127:104364.

21. Du R-H, Liang L-R, Yang C-Q, Wang W, Cao T-Z, Li M, et al. Predictors of mortality for patients with COVID-19 pneumonia caused by SARS-CoV-2: a prospective cohort study. European Respiratory Journal. 2020;55(5).

22. Abrishami A, Khalili N, Dalili N, Tabari RK, Farjad R, Samavat S, et al. Clinical and radiologic characteristics of COVID-19 in patients with CKD. Iranian journal of kidney diseases. 2020;14(4):267-77.

23. Meng J, Xiao G, Zhang J, He X, Ou M, Bi J, et al. Renin-angiotensin system inhibitors improve the clinical outcomes of COVID-19 patients with hypertension. Emerging microbes \& infections. 2020:9(1):757-60

24. Chen T, Dai Z, Mo P, Li X, Ma Z, Song S, et al. Clinical characteristics and outcomes of older patients with coronavirus disease 2019 (COVID-19) in Wuhan, China: a single-centered, retrospective study. The Journals of Gerontology: Series A. 2020;75(9):1788-95

25. Wu B, Zhou J, Wang W, Yang H, Xia M, Zhang B, et al. Association Analysis of Hyperlipidemia with the 28-Day All-Cause Mortality of COVID-19 in Hospitalized Patients. Chinese Medical Sciences Journal. 2021;36(1):17-26. 